\title{
Effects of Flame Retardant on the Behavior and Temperature Profiles of Flames Spreading over Paper
}

\author{
KENJI SATO, KATSUHIRO SUZUKI, YASUHIRO SAKAI and SETSUKO SEGA \\ Department of Physics \\ Toho University \\ Funabashi, Chiba 274, Japan
}

\begin{abstract}
Experiments of flame spread over a filter paper treated with a solution of flame retardant, $\mathrm{NH}_{4} \mathrm{H}_{2} \mathrm{PO}_{4}$ or $\mathrm{NaHCO}_{3}$, were conducted in an upward opposed air flow. The flame spread rate and temperature profiles of gas phase/paper surface were examined. Except promoted flame spread with small addition of $\mathrm{NH}_{4} \mathrm{H}_{2} \mathrm{PO}_{4}$, these agents retarded the flame spread rate and reduced the critical flow velocity for spread. $\mathrm{NH}_{4} \mathrm{H}_{2} \mathrm{PO}_{4}$ decreased the pyrolysis zone temperature more than $100 \mathrm{~K}$ while $\mathrm{NaHCO}_{3}$ decreased 20 or $30 \mathrm{~K}$ at most. With increasing add-on rate, the flame leading edge location receded and also the flame stand-off distance increased. The leading edge practically corresponded to $1400 \mathrm{~K}$ isotherm tip. The slowly ascending flame temperature distribution near the leading edge, observed for $\mathrm{NH}_{4} \mathrm{H}_{2} \mathrm{PO}_{4}$ addition, suggested diluted pyrolysis gas, and another type of flame temperature distribution observed for $\mathrm{NaHCO}_{3}$ addition suggested inhibition effects in flame reaction zone.
\end{abstract}

KEYWORDS: Flame Retardant, Flame Spread, Temperature Profiles, $\mathrm{NH}_{4} \mathrm{H}_{2} \mathrm{PO}_{4}, \mathrm{NaHCO}_{3}$

\section{INTRODUCTION}

The retardation of spread rate and also the reduction of stability range of the flame spreading over combustible materials are parts of major purposes of using flame retardant. Although many results or suggestions have been compiled from fundamental studies on the inhibition mechanisms acting in reaction processes in flame or pyrolysis(gasification), appropriate interpretations of the overall effects of flame retardant on spreading flame and also the dominant mechanisms of them are still difficult because flame spread includes transport processes of momentum, mass, energy, species, and interplays of these processes.

While for very slow flame spread over thick materials treated with flame retardant several results were obtained about the temperature or concentration profiles by in-situ measurement, basic knowledge of the structure around flame is still deficient for approaching to further understanding of the flame spread phenomena over flame-retarded materials, especially over flame-retarded paper sheet in spite that many groups of fire research have been interested in flame spread over paper sheet[1,2].

In the present study, to shed some light on the features of the structure around a spread- 
ing flame affected by flame retardant, experiments of flame spread over a filter paper sheet treated with solution of $\mathrm{NH}_{4} \mathrm{H}_{2} \mathrm{PO}_{4}$ (monoammonium phosphate, $\mathrm{MAP}$ ) or $\mathrm{NaHCO}_{3}$ (sodium hydrogencarbonate) were conducted in an air stream, and the flame spread behavior/spread rate, and the gas phase/paper surface temperature profiles were compared with these of the untreated filter paper sheet. Based on the experimental results, the mechanisms of flame spread retardation were discussed briefly.

\section{EXPERIMENTAL}

The flame spread experiment was conducted in a vertical duct having a $4 \times 4-\mathrm{cm}$ cross section(Fig. 1(a)). The duct was mounted on the exit of the converging nozzle of a wind tunnel, and air was supplied by a compressor. The relative humidity of the air flow was kept less than $10-12 \%$.

The filter paper sheet used for the experiments had a surface area of $3.9 \times 13-\mathrm{cm}$ and was $0.26 \mathrm{~mm}$ thick(Advantec No.2). The original filter paper is essentially pure cellulose; ash < $0.1 \%$. The flame-retarded paper sheet was made by immersing the filter paper into a solution of flame retardant, $\mathrm{NH}_{4} \mathrm{H}_{2} \mathrm{PO}_{4}$ or $\mathrm{NaHCO}_{3}$, for $5 \mathrm{~min}$, and then the treated paper was dried for $24 \mathrm{~h}$ at room temperature and $30 \mathrm{~min}$ at $323 \mathrm{~K}$. The paper was stored in a dessicator for more than $24 \mathrm{~h}$ until used. In the experiments, the paper was installed vertically along the center of the duct with two lines of needle, and its top edge was ignited simultaneously by electrically heated nichrome wire or thin torch.

Flame spread was observed through two quartz plates serving as duct walls. The flame spread rate in each run was determined at vertical centerline as a mean value in a $30 \mathrm{~mm}$ zone from a position $40 \mathrm{~mm}$ from the ignited end, by measuring the elapsed time for the movement of the pyrolysis zone front which was indicated by blackening of the paper surface, since the distance between the flame leading edge and the pyrolysis zone front was practically constant

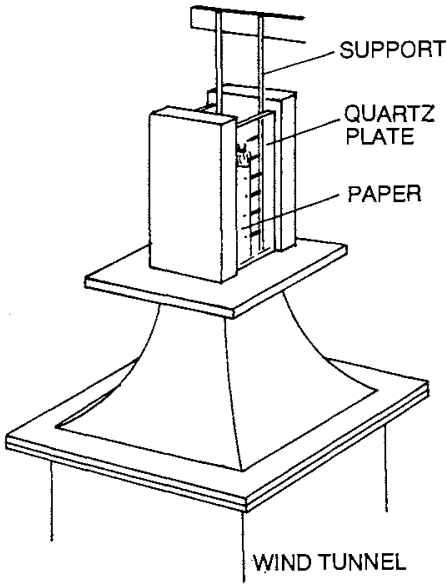

(a) VERTICAL DUCT

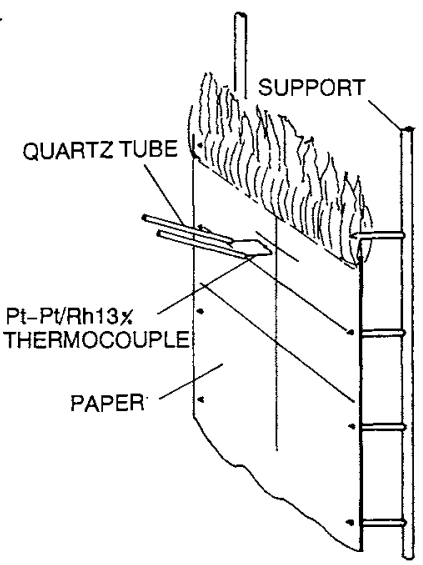

(b) THERMOCOUPLE SETUP

FIGURE 1. Experimental apparatus. 
through a run. Through this measurement zone, overall flame spread phenomena showed little change.

Temperature of gas phase or paper surface was measured by a thermocouple prepared from $25 \mu \mathrm{m}$ diameter Pt-Pt 13\% Rh wires and coated with silica(Fig. 1(b)). The thermocouple was placed at a fixed position in the middle of the zone for flame spread rate measurement, and the temperature-time diagram was recorded by using digital recorder and PC. The recorded data were transformed into temperature-position diagram in order to yield temperature profiles. The location of each thermocouple relative to the paper surface was determined carefully from enlarged video recorded image so as to identify the pyrolysis zone front and also eliminate the influence of distortion of paper during a run. The thermocouple error due to radiation was not corrected.

\section{RESULTS AND DISCUSSION}

\section{Behavior of Spreading Flame}

Flame spread behavior depends on the air flow velocity. Figure 2 shows variations of the flame spread rate with free-stream velocity, add-on rate of flame retardant agent being parameter. In the figure, (a) and (b) show the results for $\mathrm{NH}_{4} \mathrm{H}_{2} \mathrm{PO}_{4}$ and $\mathrm{NaHCO}_{3}$, respectively. The add-on rate $Y_{R}$ represents the added mass of agent divided by the mass of original filter paper sheet. The free-stream velocity $U$ was determined at the inlet of the duct.

In downward flame spread over an untreated filter paper in an opposed flow, the flame can spread under appropriate flow velocities[3]. Within the range where the flame spread rate $V_{f}$ decreases slowly with the increase of $U$, flame spread is stable. At a higher value of $U$ where $V_{f}$ begins to drop steeply, the flame leading edge cannot maintain straight line and the burning zone becomes sawtooth-like. As $U$ increases further, local blow off occurs and the remained flame zone spreads with large inclined angle. Above a critical flow velocity, no flame spreads.

In case of $\mathrm{NH}_{4} \mathrm{H}_{2} \mathrm{PO}_{4}$ addition, for very small $\mathrm{Y}_{\mathrm{R}}$, e.g., $0.1 \%$ which is much smaller than generally adopted values for practical use, $V_{\mathrm{f}}$ exceeded that of untreated paper almost uniformly over entire stable spread region. By increasing $Y_{R}$, the flame spread rate turned to decrease with smaller decrement for smaller $U$, resulting in increased dependence of $V_{\mathrm{f}}$ on $U$. At $Y_{R}=0.6 \%$, the retardation effect on $V_{f}$ was observed for $U>30 \mathrm{~cm} / \mathrm{s}$, and the critical free-stream velocity was smaller than that of untreated case. As $Y_{R}$ was increased further,

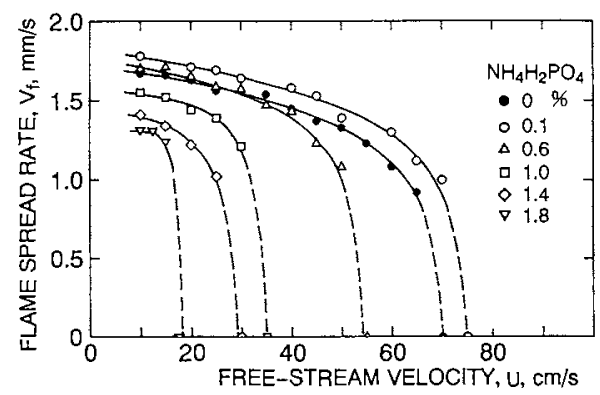

(a)

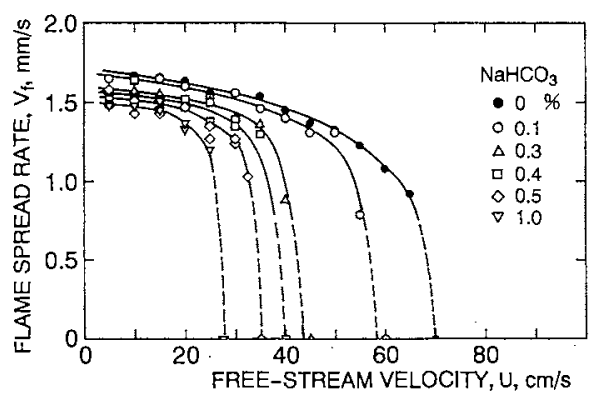

(b)

FIGURE 2. Dependence of the flame spread rate $V_{f}$ on the free-stream velocity $U . Y_{R}$ : add-on rate. (a) $\mathrm{NH}_{4} \mathrm{H}_{2} \mathrm{PO}_{4}$, (b) $\mathrm{NaHCO}_{3}$. 


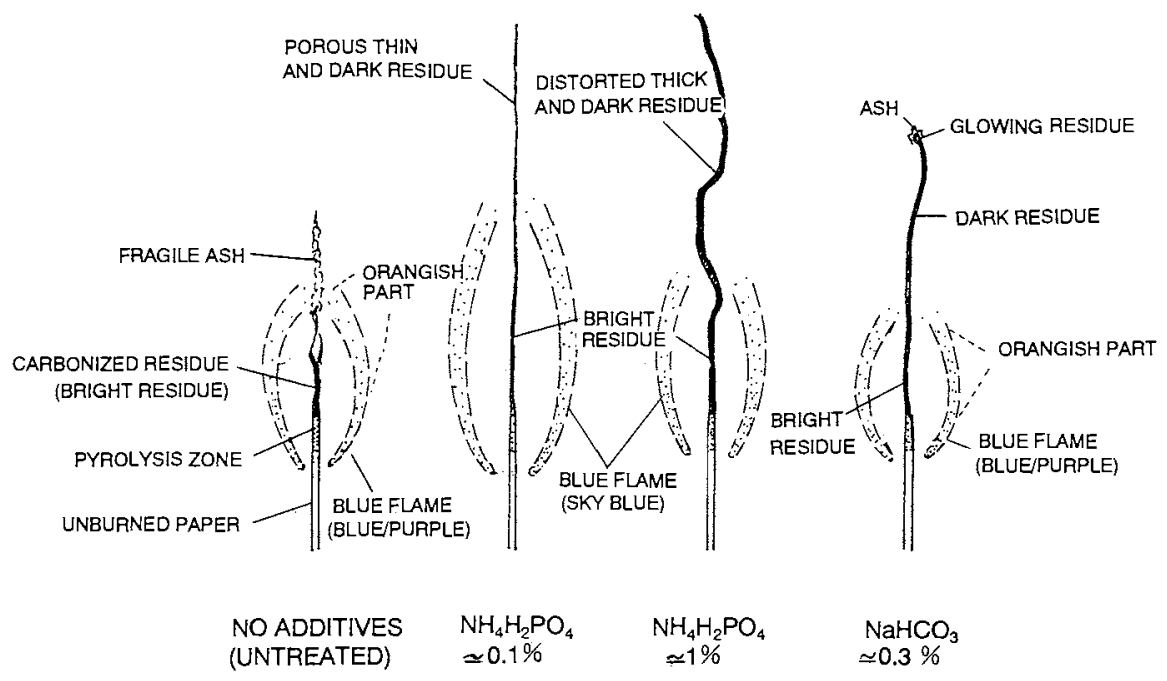

FIGURE 3. Schematic illustration of the burning zones in stable flame spread.

both of stable and unstable spread region shrank remarkably with gradual decrease of $V_{f}$ at stable spread region. Above $\mathrm{Y}_{\mathrm{R}}=1.4 \%$, the decrease of $\mathrm{V}_{\mathrm{f}}$ became slight. At $\mathrm{Y}_{\mathrm{R}}>1.8 \%$, extinction occurred even in natural convection condition.

In case of $\mathrm{NaHCO}_{3}$ addition, monotonous decreases of both $\mathrm{V}_{\mathrm{f}}$ and critical free-stream velocity were observed at first with increasing $\mathrm{Y}_{\mathrm{R}}$ from zero. Above $0.4 \%$, relatively large scatter of flame spread rate occurred and the change of the mean value of scattered data became very small until the critical add-on rate at which extinction at low $U$ appeared. However, even in the range of $Y_{R}$ accompanied by large scatter of $V_{f}$, the critical free-stream velocity decreased in order. Flames spreading with large $\mathrm{Y}_{\mathrm{R}}$, at which stable spread region was narrow, were very sensitive to small disturbances.

The appearance of the burning zone in flame spread changed depending on the kind of agent. Figure 3 schematically shows the views of stable burning zone. For original filter paper sheet, a bow-shaped blue/purple flame spread, its trailing part being somewhat luminous and orange. The pyrolysis(thermal degradation) zone in a paper distinguished by the blackening due to char(carbonized residue) formation was observed behind the flame leading edge. Following this zone, a little brighten carbonized residue zone was torn up in stems of one or two $\mathrm{mm}$ wide. As the torn-up residue zone approached to the trailing part of the flame, it glowed intensely and changed to fragile white ash, which disappeared after a while.

When the promoted flame spread over the paper with small add-on rate of $\mathrm{NH}_{4} \mathrm{H}_{2} \mathrm{PO}_{4}$, large changes of the appearance were observed. The flame was prolonged, and the color changed to pale sky blue throughout the flame. The chemiluminescence of the flame was weak, and then the flame shape was somewhat vague. The pyrolysis zone was light brown. The region of bright residue beneath the flame was also stretched. At the downstream of the trail of the flame, a porous and smooth thin-film of black carbonized residue was left. As $\mathrm{Y}_{\mathrm{R}}$ was increased further, the flame length turned to decrease and the intensity of chemiluminescence augmented. The color of the pyrolysis zone became deep. The carbonized residue was thickened, and wrinkling or shrinkage of the cooled residue behind the flame was ob- 
served. The wrinkled residue was torn up in two or three parts.

The addition of $\mathrm{NaHCO}_{3}$ did not change the flame color so much, although the flame length decreased with increasing $\mathrm{Y}_{\mathrm{R}}$. In the solid phase, however, the aspect of the carbonized residue changed. As $\mathrm{Y}_{\mathrm{R}}$ was increased, the length of the residue zone increased and it tore up scarcely. Unlike the case of $\mathrm{NH}_{4} \mathrm{H}_{2} \mathrm{PO}_{4}$, however, the long residue zone disappeared steadily at a locally glowing narrow region distant from the flame zone. This glowing part was covered by thin small ash.

\section{Temperature Profiles}

Temperature-time diagrams were examined for both of gas phase and paper surface, with $\mathrm{U}$ being $25 \mathrm{~cm} / \mathrm{s}$. In order to investigate the temperature distributions or profiles, the recorded temperature-time diagram was transformed into temperature-position diagram by calculating the relative distance measured from the moving pyrolysis zone front by using $V_{f}$ in each run with assuming steady spread.

Figure 4 shows examples of the temperature-position diagram. $x$ is the distance along the paper surface measured from the pyrolysis zone front which was defined as the front of the blackening zone. The pyrolysis zone side is positive. Even though the pyrolysis zone front in this study does not have rigorous meaning in chemically or physically, it is convenient to identify the relative location for the same experimental condition. $y$ is the distance in the gas phase measured from the unbumed paper surface. As the coordinate is fixed to the spreading flame, the paper moves toward right hand side with $V_{\mathrm{f}}$ Although at relatively large $\mathrm{Y}_{\mathrm{R}}$ distortion of carbonized residue sometimes disturbed the temperature history particularly around the latter half of flame zone, by checking such cases from video recorded image and reliable data were chosen to deduce temperature profiles. In the measurements of surface temperature, the paper surface was carefully dented to fit and hold the thermocouple junction, and then reproducible data were obtained.

Figure 5 shows the variation of the temperature distributions at the paper surface with $Y_{R}$. $T_{S}$ is the surface temperature. When $Y_{R}=0$, from a little behind the pyrolysis zone front, $a$ region of practically uniform temperature, about $830 \mathrm{~K}$, extended over about one and a half $\mathrm{mm}$. From the end of this region the temperature rose again. The end also approximately

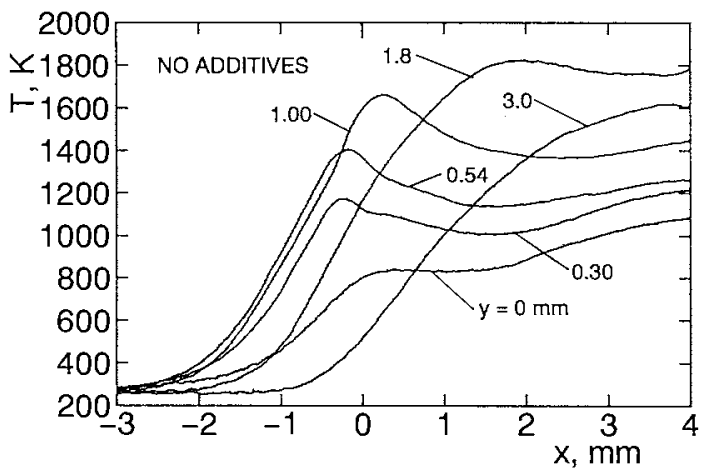

FIGURE 4. Examples of the temperature-position diagram. $x$ : distance along the paper surface measured from the pyrolysis zone front, $y$ : distance in the gas phase measured from the unburned paper surface. (untreated case, $\mathrm{U}=25 \mathrm{~cm} / \mathrm{s}$ ) 


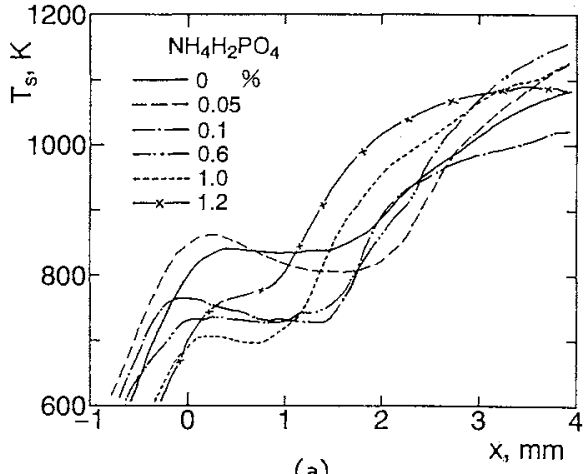

(a)

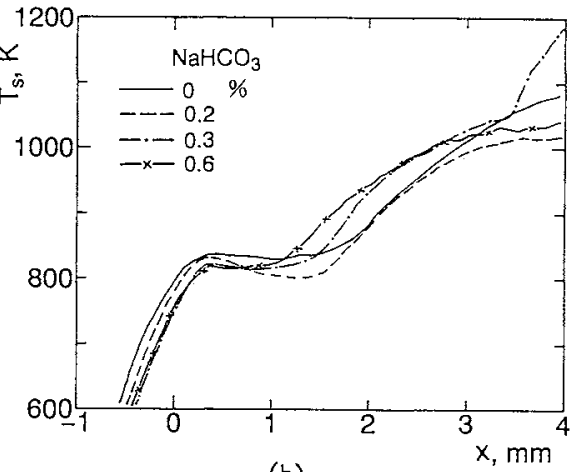

(b)

FIGURE 5. Temperature distributions at the paper surface. $T_{S}$ : surface temperature. (a) $\mathrm{NH}_{4} \mathrm{H}_{2} \mathrm{PO}_{4}$, (b) $\mathrm{NaHCO}_{3}$. (U $\left.=25 \mathrm{~cm} / \mathrm{s}\right)$

corresponded to the end of blackening zone. As it must be reasonable to consider that intense endothermic pyrolysis reaction occurs at this uniform temperature region, in the following, the region of essentially uniform temperature distribution will be called as 'main pyrolysis zone'.

In the figure, (a) represents the results for $\mathrm{NH}_{4} \mathrm{H}_{2} \mathrm{PO}_{4}$. At $\mathrm{Y}_{\mathrm{R}}=0.05 \%, \mathrm{~T}_{\mathrm{S}}$ gradually descended along the pyrolysis zone after taking a peak value at positive $\mathrm{X}$, where $\mathrm{T}_{\mathrm{S}}$ exceeded the temperature of the main pyrolysis zone at $Y_{R}=0$. With further increase of $Y_{R}$, the point of the temperature rise resumption became more clear. At $Y_{R}=0.1 \%$, the location of the peak shifted to $\mathrm{x}=0$ and the temperature at the main pyrolysis zone dropped. The drop measured at the end of the zone was approximately $100 \mathrm{~K}$; similar large drop of the pyrolysis temperature due to $\mathrm{NH}_{4} \mathrm{H}_{2} \mathrm{PO}_{4}$ was already reported by fundamental studies by TG [4]. At larger $\mathrm{Y}_{\mathrm{R}}$, this temperature approached to about $700 \mathrm{~K}$ as long as the flame spread was stable. However, when flame spread became unstable, this temperature became higher with scattering(e.g., $\left.\mathrm{Y}_{\mathrm{R}}=1.2 \%\right)$. In the latter case, the temperature gradually ascended along the pyrolysis zone. It can be seen that the main pyrolysis zone length decreases with $\mathrm{Y}_{\mathrm{R}}$.

As is shown in (b), for $\mathrm{NaHCO}_{3}$ addition, the location of the main pyrolysis zone front in $\mathrm{x}$ was almost independent of $\mathrm{Y}_{\mathrm{R}}$. Although $\mathrm{T}_{\mathrm{S}}$ at preheat zone seems to decrease relatively with increasing $\mathrm{Y}_{\mathrm{R}}$, the temperature decrease at the front of the main pyrolysis zone was not so large. At the latter part in the main pyrolysis zone, $T_{S}$ dropped at first with $Y_{R}$, but with further increase of $Y_{R}$ it soon turned to slight increase. The essential maximum drop of $T_{S}$ at the pyrolysis zone is 20 or $30 \mathrm{~K}$ at most. The main pyrolysis zone length decreased with $\mathrm{Y}_{\mathrm{R}}$ like for $\mathrm{NH}_{4} \mathrm{H}_{2} \mathrm{PO}_{4}$ addition. These decreases of the main pyrolysis zone length are considered to be related with the decrease of $\mathrm{V}_{f}$ because it increases the residence time of the paper element in passing through unit length of pyrolysis zone.

Figure 6 shows the variations of the temperature profiles in the gas phase. (a) is of unretarded case. Three cases are represented for $\mathrm{NH}_{4} \mathrm{H}_{2} \mathrm{PO}_{4}$ addition; (b) for promoted flame spread, (c) for the case that the flame spread rate was almost the same as that of the untreated case, (d) for retarded flame spread. Since in the case of $\mathrm{NaHCO}_{3}$ addition $\mathrm{V}_{\mathrm{f}}$ scattered for $\mathrm{Y}_{\mathrm{R}}$ $>0.4 \%$, only one case was examined for $\mathrm{NaHCO}_{3}(\mathrm{e})$.

The relation between the rough location of the flame leading edge observed by eye(chemiluminescence) and the temperature profiles around it was examined at first. By comparison, it 


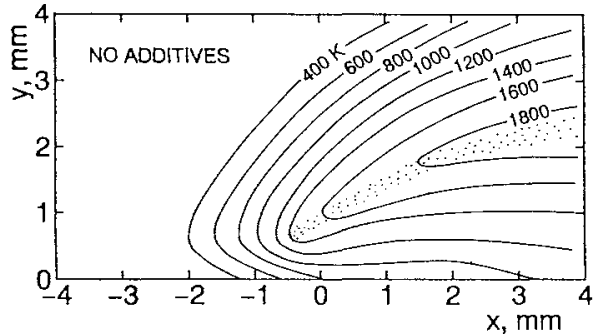

(a)

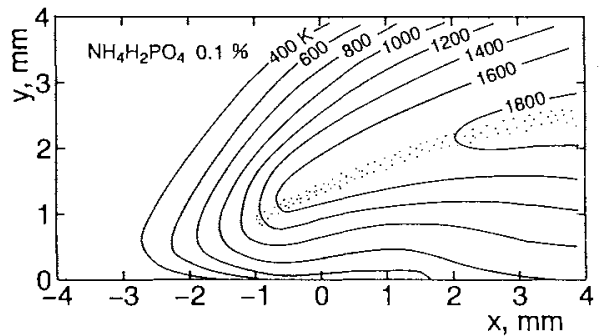

(b)

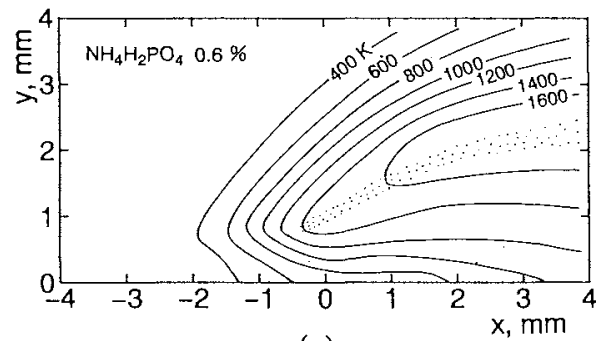

(c)

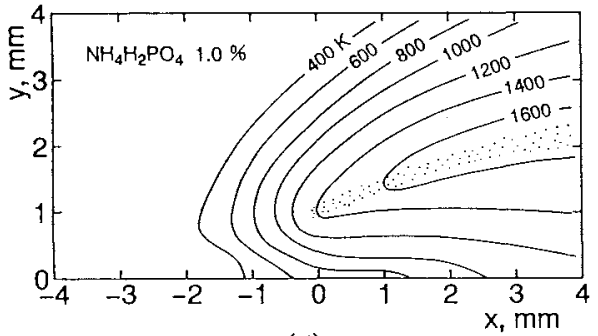

(d)

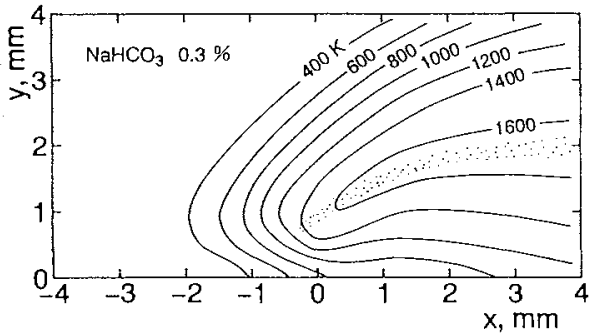

(e)

FIGURE 6. Temperature profiles in the gas phase.(a)untreated case,(b) $\mathrm{NH}_{4} \mathrm{H}_{2} \mathrm{PO}_{4} 0.1 \%$, (c) $\mathrm{NH}_{4} \mathrm{H}_{2} \mathrm{PO}_{4} 0.6 \%$, (d) $\mathrm{NH}_{4} \mathrm{H}_{2} \mathrm{PO}_{4} 1.0 \%$, (e) $\mathrm{NaHCO}_{3} 0.3 \%$. (U = $\left.25 \mathrm{~cm} / \mathrm{s}\right)$

was shown that in each case the location of observed flame leading edge approximately corresponded to the tip or apex of $1400 \mathrm{~K}$ isotherm and that in most cases the distance between the tips of adjacent isotherms changed noticeably at $1400 \mathrm{~K}$. Accordingly, it was inferred that in the present study the tip of $1400 \mathrm{~K}$ practically corresponds to the reaction zone front(or simply, flame leading edge), being independent of $\mathrm{Y}_{\mathrm{R}}$.

In untreated case(Fig. 6(a)), the gas phase temperature rise started from 3 or $4 \mathrm{~mm}$ ahead of the pyrolysis zone front. The location of the flame leading edge in $x$ was -0.4 or $-0.5 \mathrm{~mm}$. The flame stand-off distance, i.e., the distance between the flame leading edge and paper surface, was about $0.6 \mathrm{~mm}$. From the flame leading edge, the temperature gradually increased along the reaction zone. At the region between the flame leading edge and preheat zone surface, the isotherms were inclined a little from the surface. The maximum of the temperature gradient ( $\mathrm{T} / \partial \mathrm{y}$ ) at the surface exceeded $1000 \mathrm{~K} / \mathrm{mm}$. In the gas phase adjacent to the pyrolysis zone the isotherms were almost parallel to the surface, and behind it the isotherms gradually approached to the surface. Overall features of the deduced temperature profiles are similar to those obtained by numerical studies[2,5]. 


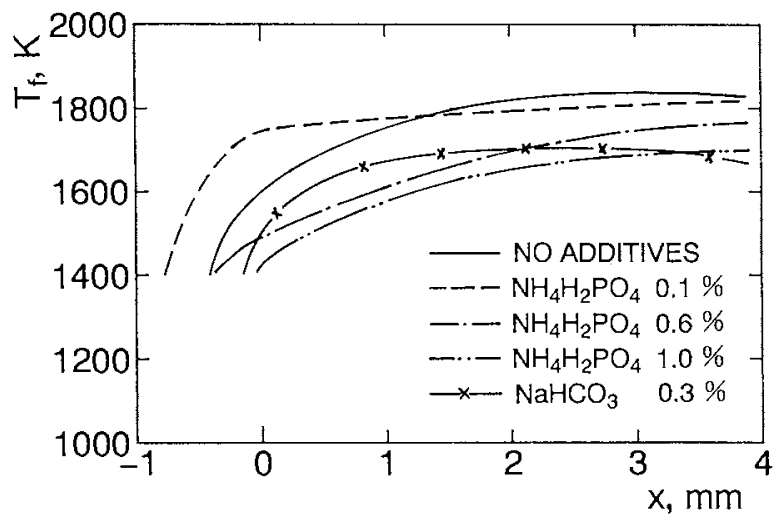

FIGURE 7. Distribution of flame temperature $T_{f}$ along $x$ direction. ( $U=25 \mathrm{~cm} / \mathrm{s}$ )

When promoted flame spread at $\mathrm{NH}_{4} \mathrm{H}_{2} \mathrm{PO}_{4} 0.1 \%$, the flame temperature near the leading edge was relatively high and the tip of $1400 \mathrm{~K}$ isotherm was loosely rounded and shifted toward the unburned part(Fig. 6(b)). The flame stand-off distance increased to 0.9 to 1.0 $\mathrm{mm}$. Near the preheat zone, the inclination of the isotherm was small. Although the preheat zone length of the paper seems to be much longer, as the front of the main pyrolysis zone moved about $0.4 \mathrm{~mm}$ toward negative $\mathrm{x}$ as shown in Fig. 5(a) the net increase of the preheat zone length is smaller. Behind the pyrolysis zone end, isotherms near the surface approached to the surface more rapidly.

As add-on rate of $\mathrm{NH}_{4} \mathrm{H}_{2} \mathrm{PO}_{4}$ was increased to $0.6 \%$, the value of $\mathrm{V}_{\mathrm{f}}$ returned to that of untreated paper sheet. However, the aspects of the temperature profiles differed (Fig. 6(c)). For examples, the flame stand-off distance became a little larger, and in $\mathrm{x}$ direction, the distance between the flame leading edge and the front of the main pyrolysis zone became a little smaller although $\mathrm{x}$ position of the flame leading edge was almost the same for the two cases. At the preheat zone, the inclination of the isotherms near the paper surface was large.

At $\mathrm{NH}_{4} \mathrm{H}_{2} \mathrm{PO}_{4} 1.0 \%$, where the flame spread was retarded about $10 \%$, the tip of $1400 \mathrm{~K}$ isotherm shifted back close to $x=0$ (Fig. $6(\mathrm{~d})$ ), resulting in very small distance in $\mathrm{x}$ between the flame leading edge and the main pyrolysis zone front. The flame stand-off distance increased further. The inclination of isotherms at the preheat zone surface was very large. Further increase of $Y_{R}$ made flame spread unstable gradually.

At $\mathrm{NaHCO}_{3} 0.3 \%$, the flame front receded 0.2 or $0.3 \mathrm{~mm}$ and the distance in $\mathrm{x}$ between the flame leading edge and the front of the main pyrolysis zone decreased(Fig. 6(e)). The flame stand-off distance increased about $0.2 \mathrm{~mm}$, and the angle between the isotherm and the surface at the preheat zone also increased. Although these variations are similar to that of retarded case by $\mathrm{NH}_{4} \mathrm{H}_{2} \mathrm{PO}_{4}$ addition, it is seen that the loosely rounded tip of $1400 \mathrm{~K}$ isotherm is different.

In order to explore the features of examined flames more by simple form, distributions of the flame temperature $T_{f}$ measured at the reaction zone were compared along $\mathrm{x}$ direction(Fig. 7) although there are some difference between the temperature gradient along the ridge(center) of the reaction zone and $\partial T_{f} / \partial x$. The indicated range of temperature is restricted to above $1400 \mathrm{~K}$ since the temperature at the flame leading edge was inferred to be practically $1400 \mathrm{~K}$ as was mentioned before. 
In the case of untreated filter paper, $\partial \mathrm{T}_{f} / \partial \mathrm{x}$ at the flame leading edge is $10^{3} \mathrm{~K} / \mathrm{mm}$, and $\mathrm{T}_{f}$ approaches with gradual decrease of the gradient to its maximum value $1850 \mathrm{~K}$ reached at around $\mathrm{x}=2.5-3.0 \mathrm{~mm}$.

At $\mathrm{NH}_{4} \mathrm{H}_{2} \mathrm{PO}_{4} 0.1 \%$, the temperature gradient at the flame leading edge takes almost the same value as the untreated case. This initial increment continues longer in $\mathrm{x}$ direction and $\mathrm{T}_{f}$ reaches to $1750 \mathrm{~K}$ within $0.5 \mathrm{~mm}$, and following this increase relatively flat temperature distribution continues for long length. On the contrary, in retarded flame spread cases at $\mathrm{NH}_{4} \mathrm{H}_{2} \mathrm{PO}_{4} 0.6 \%$ or $1.0 \%$, the gradient at the flame leading edge takes smaller values than that of untreated case and then $T_{f}$ slowly ascends toward the peak at $x=4 \mathrm{~mm}$.

In the case of $\mathrm{NaHCO}_{3} 0.3 \%$, the gradient at the flame front has almost the same value as the unretarded case. However, the decrease of the gradient with $\mathrm{x}$ is more sharp. Consequently, the temperature peak position approaches to the leading edge and the peak temperature is lower than that of untreated case. If the leading edge of this flame is superimposed to that of untreated case, the difference of $T_{f}$ between them increases monotonously in $x$ direction.

\section{Mechanisms of Flame Spread Retardation}

As was pointed out by many previous works, flame inhibitions by flame retardant are complex phenomena particularly for burning of combustible solids. In the following, the mechanisms of the retardation of flame spread with flame retardant will be briefly discussed principally from a view point of the relation between the experimental results in this study and the well recognized or supposed properties of examined flame retardant.

For flame spread over paper in an opposed gas flow, it is well known that spread behavior are closely related to the conditions around the flame leading edge $[1-3,5]$.

The conditions at the flame leading edge are obviously affected by the aspect of evolution of the pyrolysis gas or the pyrolysis zone condition. The typical temperature of the pyrolysis zone was about $830 \mathrm{~K}$ for the untreated paper. Although the obtained temperatures were higher than the values obtained in usual thermo analyses, these high temperatures are considered to be attributed to high heating rate near the flame leading edge[6].

The important actions of $\mathrm{NH}_{4} \mathrm{H}_{2} \mathrm{PO}_{4}$ as flame retardant are generally recognized to occur in condensed phase after changing to phosphoric acid, and these actions are (1)promotion of char formation through desiccation reaction resulting in the reduction of the generation of combustible gases or dilution of them(e.g., the path to $\mathrm{H}_{2}$ changes to $\mathrm{H}_{2} \mathrm{O}$ vapor, and carbon compounds to solid carbon), (2) reduction of the pyrolysis reaction temperature, and complementary, (3) formation of glass to interrupt gasification. The actions (1) and (3) are expected to retard the reaction rate at flame. The sharp resumption of the increase of $T_{s}$ behind the pyrolysis zone observed for $\mathrm{NH}_{4} \mathrm{H}_{2} \mathrm{PO}_{4}$ addition is considered to indicate rapid and intense charring reaction in the pyrolysis zone. The formation of glass was not confirmed since the precise analysis of the surface were not conducted. On the other hand, the action (2) itself may become a factor to reduce the heat necessary to rise the unburned paper temperature to initiate pyrolysis reactions and may yield a large flame spread rate if other situations are not changed.

The relatively low flame temperature region widely extended near the flame leading edge at $\mathrm{NH}_{4} \mathrm{H}_{2} \mathrm{PO}_{4} 0.6$ or $1.0 \%$ addition(Fig. 7) must indicate relatively uniform supply of diluted combustible pyrolysis gases to the flame(the action (1)). Since the combustible gases are provided to the reaction zone in the flame by concentration gradient and at the leading edge the combustible pyrolysis gases are diluted further by incoming air, it is reasonable to say that, when the diluted combustible gases come toward the flame, the location to maintain the minimum reaction rate moves to downstream direction and this makes shift back of the flame 
leading edge.

In generally, by the decrease of the ejection velocity of the pyrolysis gases the decrease of flame stand-off distance is expected. However, the observed flame stand-off distance increased. Although the reason is not clear, the following possibilities might be expected. One is that by the shift back of the flame leading edge in $\mathrm{x}$ direction the $\mathrm{y}$ component of gas velocity at the flame leading edge increased by approaching to ejection area, and another one is that due to the reduction of $\mathrm{T}_{\mathrm{S}}$ at the preheat zone(Fig. 5(a)) or extension of relatively low $\mathrm{T}_{f}$ around the flame leading edge the quenching effect by the surface increased. The crossing of the curves of $\mathrm{V}_{\mathrm{f}} \mathrm{vs}$. $\mathrm{U}$ for $\mathrm{Y}_{\mathrm{R}}=0$ and $0.6 \%$ is expected to be partly attributed to the increase of the stand-off distance because the large stand-off distance means that the flame leading edge is exposed at higher velocity part in the boundary layer.

The above mentioned change of the flame front location obviously reduces the heat flux from gas phase to the preheat zone. Accordingly, it can be inferred that at large add-on rate the effect of the decrease of the heat flux prevailed over that of action(2) and then the flame spread rate was retarded.

The promoted flame spread by addition of small amount of $\mathrm{NH}_{4} \mathrm{H}_{2} \mathrm{PO}_{4}$ was unique. However, similar unusual promoted burning with $\mathrm{NH}_{4} \mathrm{H}_{2} \mathrm{PO}_{4}$ or some other flame retardant were also reported already, e.g., in a study about the flame retardant test to measure the carbonized area of a inclined sample after removing attached pilot flame[7]. The most possible cause of promoted spread is supposed as that when the add-on rate is small the effect of the action(2) is transiently much larger than the effects of (1) and (3) and the combustible gases are ejected intensely from near the pyrolysis zone front. The small dependence of $V_{f}$ on $\mathrm{U}$ in spite of the large flame stand-off distance may indicate thickening of the boundary layer by intense ejection. For more pertinent understanding of the promoted phenomena further study will be necessary.

The change of flame color may suggests that phosphate compounds distributed along the reaction zone. Although there have been some suggestions that the chain-braking reaction mechanisms by phosphoric acid ion occurs in flame, the effectiveness of this mechanisms are not clear from this study.

The changes of temperature profiles of gas phase and paper surface by $\mathrm{NaHCO}_{3}$ addition are much different from that by $\mathrm{NH}_{4} \mathrm{H}_{2} \mathrm{PO}_{4}$ addition as was shown. The structure of the residue was not so strong unlike that for $\mathrm{NH}_{4} \mathrm{H}_{2} \mathrm{PO}_{4}$. Though sodium compounds are understood to promote smoldering or surface reactions [8], the point of vanishing of the carbonized residue, probably by surface reactions, was located far downstream compared to the unretarded case. The reason of it is not clear, although it is supposed to be related to the increase of carbonized component.

It is recognized that $\mathrm{NaHCO}_{3}$ is effective for inhibition of flame[9]. From Fig. 7, it was shown that by $\mathrm{NaHCO}_{3}$ addition the shape of flame temperature around the flame leading edge is not so changed. By comparing the result with that for $\mathrm{NH}_{4} \mathrm{H}_{2} \mathrm{PO}_{4}$, it can be expected that the combustible gases supplied to the flame, at least to the flame leading edge, are not diluted so much. On the other hand, $T_{f}$ turns to descend from relatively small $x$ with dropped peak temperature. This may indicate that the reactions in the flame are influenced as $\mathbf{x}$ increases. From Fig. 6(e), it seems that the temperature gradient normal to the reaction zone ridge is partly small and it means broadening of the reaction zone or slow down of reactions. Based on these arguments, it is supposed that in this case the flame reaction is inhibited and its effect is stronger for downstream side. Mitani suggested that the residence time of sodium ion or sodium compounds in the flame are important to increase the effectiveness on inhibition[10]. Since in this study the air flow comes along unburned part, the residence time of sodium compounds increases as $\mathbf{x}$ increases and this may explain the large temperature decrease at downstream side. 
When the above mentioned effects by $\mathrm{NaHCO}_{3}$ addition are postulated, a large question is the path of sodium or sodium compounds to the reaction zone in the flame. The decomposition temperature of $2 \mathrm{NaHCO}_{3} \rightarrow \mathrm{Na}_{2} \mathrm{CO}_{3}+\mathrm{H}_{2} \mathrm{O}+\mathrm{CO}_{2}$ is around $600 \mathrm{~K}$, and the melting point of $\mathrm{Na}_{2} \mathrm{CO}_{3}$ is $1125 \mathrm{~K}$. The observed pyrolysis zone temperature is about $800 \mathrm{~K}$. From the present experiments, it is difficult to specify the possible path. However, it might be inferred that the shift back of the flame front increases the opportunity of the attack of sodium/sodium compound toward the flame leading edge. It is also expected that if the main path is started from downstream high temperature part the decrease of the pyrolysis zone length also increases the opportunity of the attack. Although the primary cause of the shift back of the flame leading edge is not clear, the decrease of overall Damkobler number due to the increase of the characteristic chemical time and the decrease of the pyrolysis gas ejection velocity by the increase of carbonization are expected as causes of it.

In both cases of $\mathrm{NH}_{4} \mathrm{H}_{2} \mathrm{PO}_{4}$ and $\mathrm{NaHCO}_{3}$ addition, it is inferred that the shift-back of the flame leading edge produces the retardation of the flame spread rate and the reduction of the flame stability. Since numerical techniques to investigate the structure around the spreading flame over thin solid combustibles are rapidly developing[5], comparisons between the results by the parametric studies using numerical methods and the results by improved experimental studies on the burning zone structure will promote further understanding of the mechanisms of flame spread retardation.

\section{CONCLUSIONS}

Experiments of flame spread over a filter paper sheet treated with a solution of a flame retardant, $\mathrm{NH}_{4} \mathrm{H}_{2} \mathrm{PO}_{4}$ or $\mathrm{NaHCO}_{3}$, were conducted in an upward opposed air flow. Although within small add-on rate of $\mathrm{NH}_{4} \mathrm{H}_{2} \mathrm{PO}_{4}$ flame spread was promoted, for other cases theses agent retarded flame spread rate and also reduced the critical flow velocity for flame spread.

These agents increased the conversion into carbonized residue in the pyrolysis reactions and decreased the pyrolysis zone length. $\mathrm{NH}_{4} \mathrm{H}_{2} \mathrm{PO}_{4}$ addition decreased the temperature of the pyrolysis zone more than $100 \mathrm{~K}$ while $\mathrm{NaHCO}_{3}$ addition decreases 20 or $30 \mathrm{~K}$ at most.

It was inferred that the flame leading edge(reaction zone front) practically corresponds to the tip of $1400 \mathrm{~K}$ isotherm, being independent of add-on rate. With increasing add-on rate, the flame leading edge location relative to the front of the zone of endothermic pyrolysis reaction receded toward downstream side and the flame stand-off distance increased, resulting in the decrease of the heat flux from the flame to the preheat zone surface. These movement of the flame leading edge location is inferred to produce the retardation of the flame spread rate and also reduce flame stability.

The aspects of the flame zone temperature distribution differed between the two agents. The slowly ascending flame temperature distribution near the flame leading edge was observed for $\mathrm{NH}_{4} \mathrm{H}_{2} \mathrm{PO}_{4}$ addition and it suggested diluted combustible gas ejection at pyrolysis reactions. For $\mathrm{NaHCO}_{3}$ addition, the drop of flame temperature from the value of untreated case, which increased toward downstream direction, was observed and it suggested inhibition effects in the reaction zone in flame.

\section{ACKNOWLEDGEMENT}

This work was partly supported by the Association for Wallcovering Materials. The authors would like to thank Mr. N. Fujimoto, Miss Y. Takemura, Mr. M. Kurihara, and Mr. A. Nakamura for their help in conducting experiments. 


\section{REFERENCES}

1. Fernandez-Pello, A. C. and Hirano, T., "Controlling Mechanisms of Flame Spread", Combustion Science and Technology, 32, pp. 1-31, 1983.

2. Fernandez-Pello, A. C., "Flame Spread Modeling", Combustion Science and Technology, 39, 119-134, 1984.

3. Hirano, T. and Sato, K., "Effects of Radiation and Convection on Gas Velocity and Temperature Profiles of Flames Spreading over Paper", 15th Symposium(International) on Combustion, Combustion Institute, pp. 233-241, 1975.

4. Uehara,Y., "A few Problems about the Mechanisms of Flame Retardation for Polymer", Nensyo Kenkyu(Journal of Combustion Society of Japan), 39, 1-27, 1975.

5. Chen, C. H., "A Numerical Study of Flame Spread and Blowoff over a Thermally-Thin Solid Fuel in an Opposed Air Flow", Combustion Science and Technology, 69, 63-83, 1991.singular

6. Kashiwagi, T. and Nambu, H., "Global Kinetic Constants for Thermal Oxidative Degrada tion of a Cellulosic Paper", Combustion and Flame, 88, 345-368, 1992.

7. Akita, K. and Onishi, A. "Unusual Combustion Phenomena of Flame Retarded Thin Materials and Problems about Test Methods", Saigai no Kenkyu, 14, 189-196, 1983.

8. McCarter, R. J., "Smoldering Combustion of Wood Fibers: Cause and Prevention", J. of Fire and Flammability, $9,119-126,1978$.

9. Iya, K. S., Wollowitz, S., and Kaskan, W. E., "The Mechanisms of Flame Inhibition by Sodium Salts",15th Symposium(International) on Combustion, Combustion Institute, pp. 329-336, 1975.

10.Mitani,T., "Flame Retardant Effects of $\mathrm{CF}_{3} \mathrm{Br}$ and $\mathrm{NaHCO}_{3}$ ", Combustion and Flame, 50, 177-188, 1983. 